\title{
IMPACT FORCE ANALYSIS ON WAVE DISSIPATING CONCRETE BLOCKS DURING ROCKING MOTION
}

\author{
Jun Mitsui ${ }^{1}$, Masato Yamamoto ${ }^{1}$, Satoshi Noboru ${ }^{1}$ and Ichiro Nishiwaki ${ }^{1}$
}

\begin{abstract}
Breakage of wave dissipating concrete blocks occasionally occurs due to collision with other blocks during rocking motion under wave action. Therefore, an understanding of the impact forces induced by rocking blocks is important to solve this problem. The authors formulated impact forces using impact velocity, properties of materials, and dimensionless parameters depending on the shape of blocks to propose a theory to predict the magnitude of impact force. Fundamental drop tests using tetrapods were also conducted to confirm the proposed formula. Various sizes of blocks were used in the drop tests to reveal the scale effects. It is shown that predicted impact forces agree well with measured ones and that no scale effects concerning impact force seem to exist in the range of this study.
\end{abstract}

Keywords: wave dissipating concrete block; impact force; drop test

\section{INTRODUCTION}

Composite breakwaters covered with wave dissipating concrete blocks have been widely used in Japan. In recent years, breakwaters tend to be constructed in deep sea areas with severe wave conditions. Accordingly, the required mass of concrete blocks has become larger. Because relative structural strength of the block decreases with increase in the size of the block, a severer condition for strength will be imposed on the blocks. In general, external forces acting on the concrete blocks can be divided into static loads such as the surcharge loads induced by the self-weight of the blocks in the upper layer and dynamic loads such as pulsating forces due to wave attack, impact forces due to collisions between blocks, and so on. Among them, impact forces due to collisions are very difficult to evaluate. Moreover, it is considered that fracture of concrete blocks in the outer surface layer mainly occurs due to impact forces. Therefore, an understanding of the impact forces due to rocking motion of the block is important to solve this problem.

Fig. 1 shows the outline of the analysis. Waves induce rocking and collisions of blocks. Because rocking phenomena are probabilistic, it is considered that the impact velocities of each collision can be expressed as a probability distribution. The distribution is considered to be influenced by wave conditions, structural conditions, location of the block, and so on. When a block collides, the block receives impact force. The force is related to impact velocity, shape of the block, material of the block, and so on. As the impact response, stress is induced in the block. If the stress reach to critical stress, the block will break. Thus, impact phenomena due to rocking is very complicated.

As for the impact velocity, van der Meer and Heydra (1991) measured impact velocities of Cubes and Tetrapods using an accelerometer embedded in the block. However, their research concentrated on a description of distribution of impact velocities as a function of wave height and distance from stillwater level to the location of the block. The relation between impact velocities and other properties such as impact forces, strain, and stress is still not resolved. Another approach is to directly measure stress acting on the rocking block under wave action by hydraulic model tests. Nishigori et al. (1986) measured surface strain on 50kg tetrapods using strain gages. d'Angremond et al (1994) measured stresses in a tetrapod by a load-cell inserted in the block in a wave tank. They examined the parameters affecting the stress distribution. However, as their results are very scattered, it is considered that the great number of test cases would be required to obtain general conclusions.

On the other hand, drop tests (Fig. 2) are useful to directly compare the strength of individual blocks having different geometries. Since they can be done under idealized and simplified conditions, the results of the tests are less scattered. Although drop tests have been done by some researchers (e.g., Burcharth 1991), there are few researchers who have measured impact forces. If impact forces are measured during drop tests, the relation between impact velocity and impact force will become clear. Terao et al.(1982) conducted drop tests using 0.04t to 4t Dollosse and measured impact forces, but they did not produce a formula for impact forces.

In our study, the authors have formulated relationship between impact force, impact velocity, coefficients of materials, and dimensionless parameters depending on the shape of blocks. Then drop tests with measurements of impact forces and impact velocities were performed to decide the empirical

\footnotetext{
${ }^{1}$ Technical Research Institute, Fudo Tetra Corporation, 2-7, Higashi-nakanuki, Tsuchiura, Ibaraki, 300-0006, Japan
} 
parameters and to confirm the applicability of the proposed formula. Various sizes of tetrapods from $0.23 \mathrm{~kg}$ to $2880 \mathrm{~kg}$ were used for the drop tests to check if scale effects existed or not.

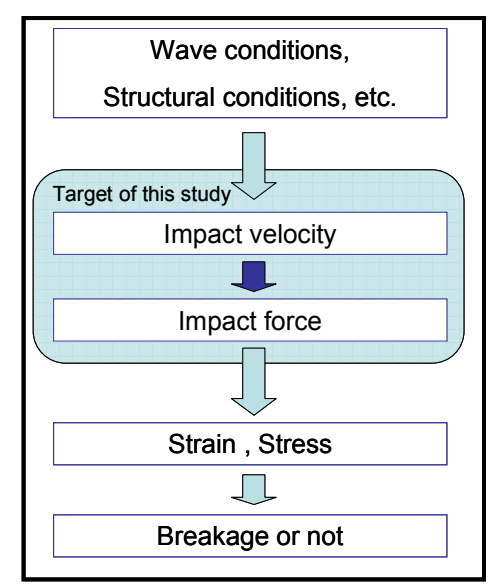

Figure 1. Impact phenomena of block.

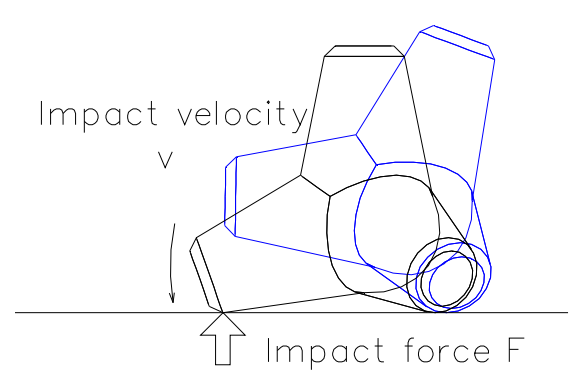

Figure 2. Schematic view of the drop test.

\section{THEORETICAL ANALYSIS}

\section{Formulation of impulse}

A typical time series of the impact force signal in the drop tests is shown in Fig. 3. In this study, impact force $F$ was defined as the maximum value of the force signal, duration of the impact $\tau$ was defined as the period from the time force start increasing to when the force becomes zero again. Impulse $P$ was defined as the time integral of the force signal.

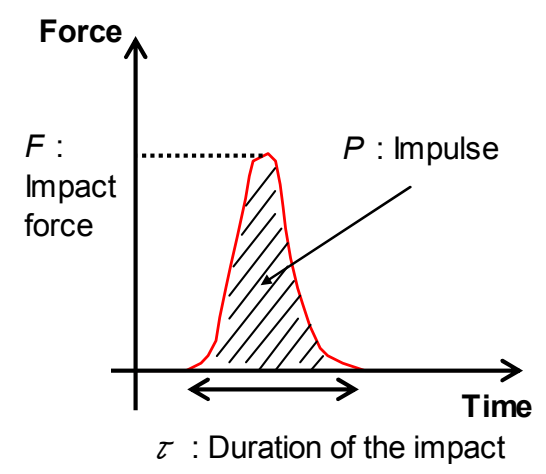

Figure 3. Typical time series of impact force signal.

Fig. 4 shows a coordinate system for the theoretical analysis. Momentum conservation equations in horizontal and vertical directions during collision are represented as follows:

$$
\begin{gathered}
m v_{x 1}-m v_{x 0}=0 \\
m v_{y 1}-m v_{y 0}=P+P^{\prime}
\end{gathered}
$$

where $m$ is the mass of the block, $P$ and $P^{\prime}$ are the impulses on collision point and rotation axis, $v_{\mathrm{x}}$ and $v_{\mathrm{y}}$ are the velocities of the center of gravity, suffixes 0 and 1 represent just before and after the impact respectively. The angular momentum equation is represented as follows:

$$
I_{g} \omega_{1}-I_{g} \omega_{0}=P^{\prime} L_{1}-P L_{2}
$$

where $I_{\mathrm{g}}$ is the moment of inertia about the center of gravity, $\omega$ is the angular velocity. 


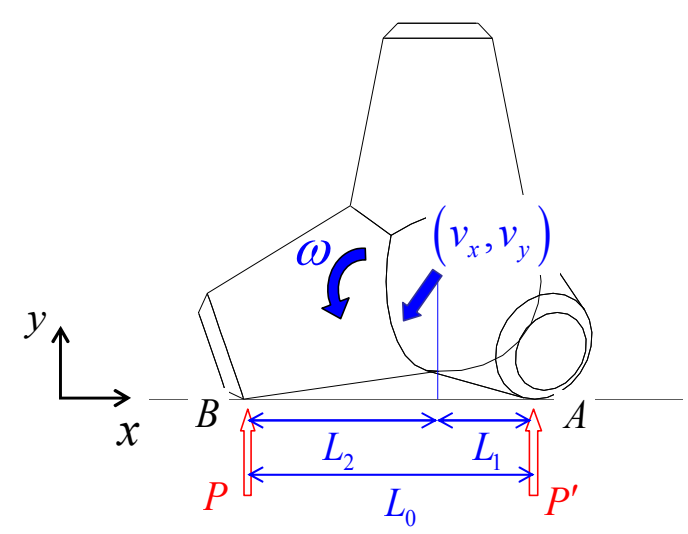

Figure 4. Coordinate system for the theoretical analysis.

If the drop height is given, $v_{\mathrm{x} 0}, v_{\mathrm{y} 0}$, and $\omega_{0}$ can be obtained by the energy conservation law. The boundary conditions at point $\mathrm{A}$ (axis of rotation) and point $\mathrm{B}$ (collision point) are given as follows:

$$
\begin{gathered}
v_{y 1}+L_{1} \omega_{1}=0 \\
v_{y 1}-L_{2} \omega_{1}=-e\left(v_{y 0}-L_{2} \omega_{0}\right)
\end{gathered}
$$

in which $e$ is the coefficient of restitution. Eq. 4 represents the condition at point A where the block must keep contact with the ground. Eq. 5 represents the condition of vertical velocity on point B. Using Eq. 1 to Eq. 5, the impulse on the collision point $P$ is expressed as follows:

$$
\begin{aligned}
P & =(1+e) \frac{L_{1}^{2}+I_{g} / m}{L_{0}^{2}} \rho D_{n}^{3} v \\
& =\alpha_{1} \rho D_{n}^{3} v
\end{aligned}
$$

where $v$ is the impact velocity on the toe of the leg, $\rho$ is the mass density of the block, $D_{\mathrm{n}}$ is the nominal diameter of the block (= cubic root of volume), $\alpha_{1}$ is a dimensionless parameter depending on the shape of the block.

\section{Formulation of duration of the impact}

The duration of the impact $\tau$ was assumed to be proportional to the time that an elastic wave travels from the point of impact to a free edge and back again. The velocity of the elastic wave is given by:

$$
c=\sqrt{E / \rho}
$$

where $E$ is the modulus of elasticity. Thus the duration of the impact $\tau$ can be expressed as follows using a dimensionless parameter $\alpha_{2}$ :

$$
\tau=\alpha_{2} \frac{D_{n}}{\sqrt{E / \rho}}
$$

\section{Formulation of impact force}

The relation between $P, F$, and $\tau$ is expressed as follows:

$$
P=\alpha_{3} F \tau
$$


in which $\alpha_{3}$ is a dimensionless parameter. If the time variation of the impact force is triangular, $\alpha_{3}=0.5$. Substituting Eq. 6 and Eq. 8 into Eq. 9, results in the following prediction formula for the impact force.

$$
F=\frac{\alpha_{1}}{\alpha_{2} \alpha_{3}} \sqrt{\rho E} D_{n}^{2} v
$$

Because the dimensionless parameters $\alpha_{1}, \alpha_{2}$, and $\alpha_{3}$ are considered to be unique for the specified block, if these values are acquired, the impact forces of the corresponding block can be determined.

\section{DROP TESTS}

\section{Test conditions}

Characteristics of the blocks used in the drop tests are shown in Table 1. The masses of the blocks range from $0.23 \mathrm{~kg}$ to $2880 \mathrm{~kg}$. The material in the $0.23 \mathrm{~kg}$ and $2.94 \mathrm{~kg}$ blocks is mortar while the others are made of concrete.

\begin{tabular}{|c|c|c|c|c|}
\hline Block & $\begin{array}{l}\text { Mass } m \\
\quad(\mathrm{~kg})\end{array}$ & Material & $\begin{array}{l}\text { Mass density } \rho \\
\left(\mathrm{kg} / \mathrm{m}^{3}\right)\end{array}$ & $\begin{array}{l}\text { Modulus of elasticity } E \\
\qquad\left(\times 10^{4} \mathrm{~N} / \mathrm{mm}^{2}\right)\end{array}$ \\
\hline \multirow{6}{*}{ Tetrapods } & 2880 & \multirow{4}{*}{ Concrete } & $\sim 2300$ & 1.94 \\
\hline & 1840 & & $\sim 2300$ & 1.89 \\
\hline & 460 & & $\sim 2300$ & 2.06 \\
\hline & 36.8 & & 2344 to 2365 & 1.95 to 2.24 \\
\hline & 2.94 & \multirow{2}{*}{ Mortar } & 2160 & 2.45 \\
\hline & 0.23 & & 2236 & 2.45 \\
\hline
\end{tabular}

Fig. 5 shows the settings of the drop tests. One horizontal leg of the block was lifted up to a given height by a crane and dropped onto a load cell with releasing a quick release hook. The load cell was carefully installed on a $1 \mathrm{~m}$ thick rigid concrete slab. In the case of blocks greater than $36.8 \mathrm{~kg}$, an accelerometer was attached on the top of the leg to obtain the impact velocities. By integrating the timeseries data of the acceleration gives the impact velocities. A high-speed video camera set was also used to obtain impact velocities.

In the case of $0.23 \mathrm{~kg}$ and $2.94 \mathrm{~kg}$ blocks, a string was used to lift up the leg. The string was cut by burning using a gas burner to release the leg quickly. In the case of the $36.8 \mathrm{~kg}$ block, a rope was used to lift up the block and release it by hand.

Three types of load cell were used according to the mass of the block. Their capacities were $5 \mathrm{kN}$, $200 \mathrm{kN}$ and $2000 \mathrm{kN}$, while their natural frequencies were $24 \mathrm{kHz}, 8.64 \mathrm{kHz}$ and $3.5 \mathrm{kHz}$, respectively. The capacity of the accelerometer used in the tests was $\pm 200 \mathrm{G}$, maximum response frequency was $3.5 \mathrm{kHz}$. A dynamic strain recorder was used to record the load and acceleration. The maximum response frequency of the recorder was $10 \mathrm{kHz}$ and the minimum sampling interval was $0.005 \mathrm{~ms}$. Highspeed video filming was conducted at 300 frame/s and 512 x 384 pixels.

The test cases are summarized in Table 2. The drop height at the top of the leg was varied and each case was repeated several times. 


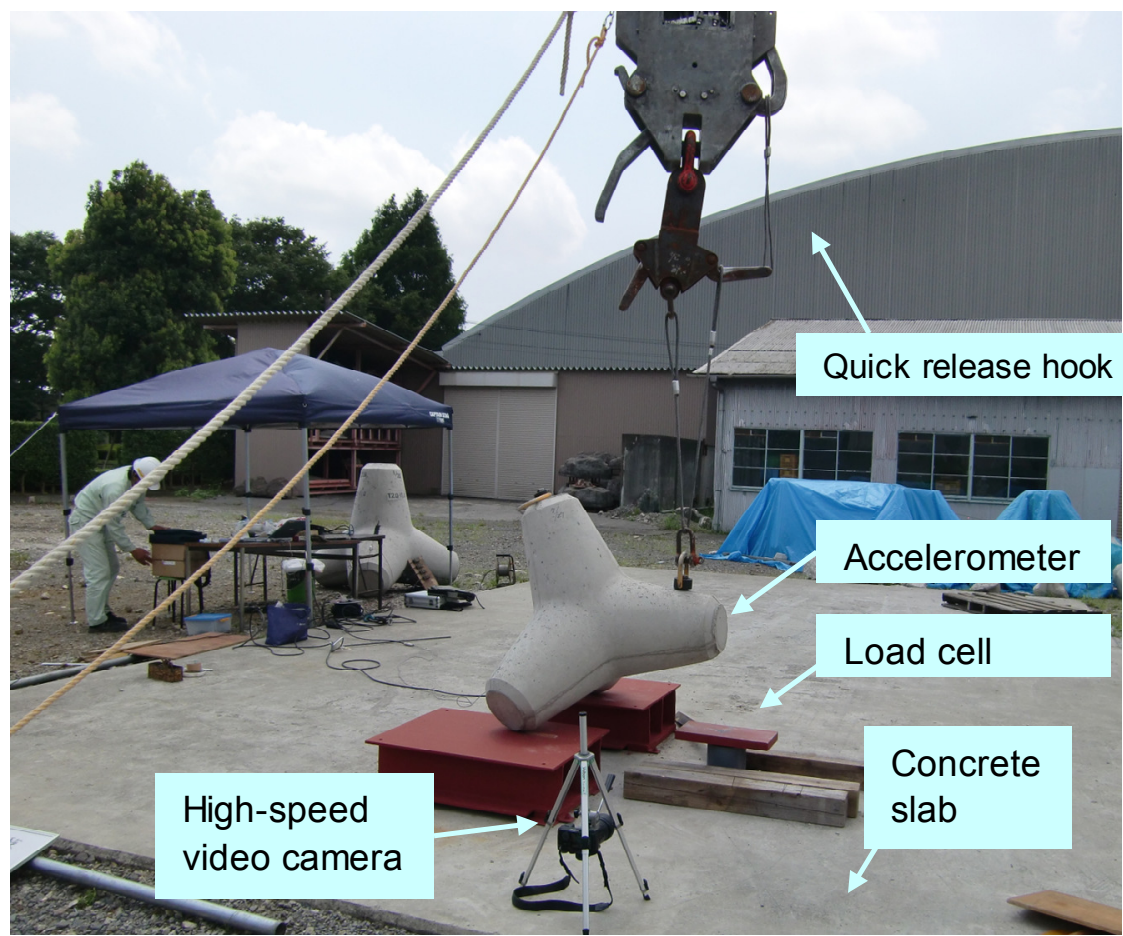

(a) $460 \mathrm{~kg}$ block

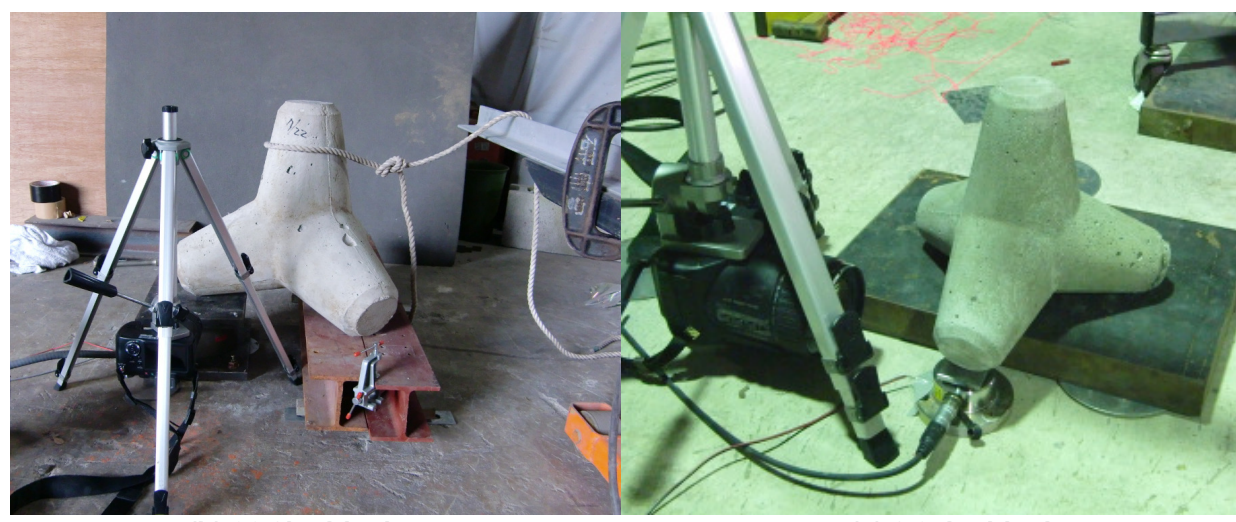

(b) $36.8 \mathrm{~kg}$ block

(c) $2.94 \mathrm{~kg}$ block

Figure 5. Drop test setup.

\begin{tabular}{|c|c|c|c|}
\hline \multicolumn{2}{|c|}{ Table 2. Test cases. } & Repetition & $\begin{array}{c}\text { Number of test } \\
\text { blocks }\end{array}$ \\
\hline$m(\mathrm{~kg})$ & $\begin{array}{c}\text { Drop height at the } \\
\text { top of the leg } \\
\Delta h(\mathrm{~cm})\end{array}$ & 3 & 1 \\
\hline 2880 & $3,5,10,15,25,40$ & 3 & 1 \\
\hline 1840 & $3,5,10,15,25$ & 3 & 1 \\
\hline 460 & $5,10,15,20$ & 2 & 3 \\
\hline 36.8 & $2,4,6,8,10,12$ & 3 & 1 \\
\hline 2.94 & $1,2,3,4,5$ & 2 & 1 \\
\hline 0.23 & $0.5,1,1.5,2,2.5$ & & \\
\hline
\end{tabular}




\section{Test Results}

In the case of the $2880 \mathrm{~kg}$ block, the block fractured at the groin when the drop height was $40 \mathrm{~cm}$. In the other cases, the blocks did not fracture or crack. In the cases where the block mass was heavier than $460 \mathrm{~kg}$, crushing near the collision point was observed.

Fig. 6 shows examples of images at the moment of impact taken with the high-speed video camera. It can be seen that the images at $\mathrm{t}=0.0367$ ( $\mathrm{s}$ ) and $\mathrm{t}=0.0400$ (s) show the states just before and after the impact respectively. Fig. 7 shows an example of calculation of impact velocity at the top of the leg. The velocity at each moment was first obtained by the distance moved by the frame rate $(=0.0033(\mathrm{~s}))$. Then, a regression line was obtained from the velocities before impact. The impact velocity was obtained from the regression line assuming that the moment of impact was the middle of the time of just before and just after impact. It can be seen that the velocities before impact are increasing as the block falls and that the acceleration is almost constant. Fig. 8 shows the measured impact velocities versus drop heights at the top of the leg. In the cases of $0.23 \mathrm{~kg}$ and $2.94 \mathrm{~kg}$ blocks, velocities obtained from the high-speed video camera were used. In the cases of $36.8 \mathrm{~kg}$ and $460 \mathrm{~kg}$ blocks, the velocities obtained from the accelerometer were used. In the cases of $1840 \mathrm{~kg}$ and $2880 \mathrm{~kg}$ blocks, the velocities obtained from the high-speed video camera were used because the dynamic strain recorder used in the tests was different from the one mentioned above, and it had poor resolution. From the preliminary test, it was confirmed that both velocities obtained from the accelerometer and high-speed video camera were almost identical. The solid line in Fig. 8 shows the calculated value from the energy conservation law. It can be seen that the measured values agree with the calculated ones.
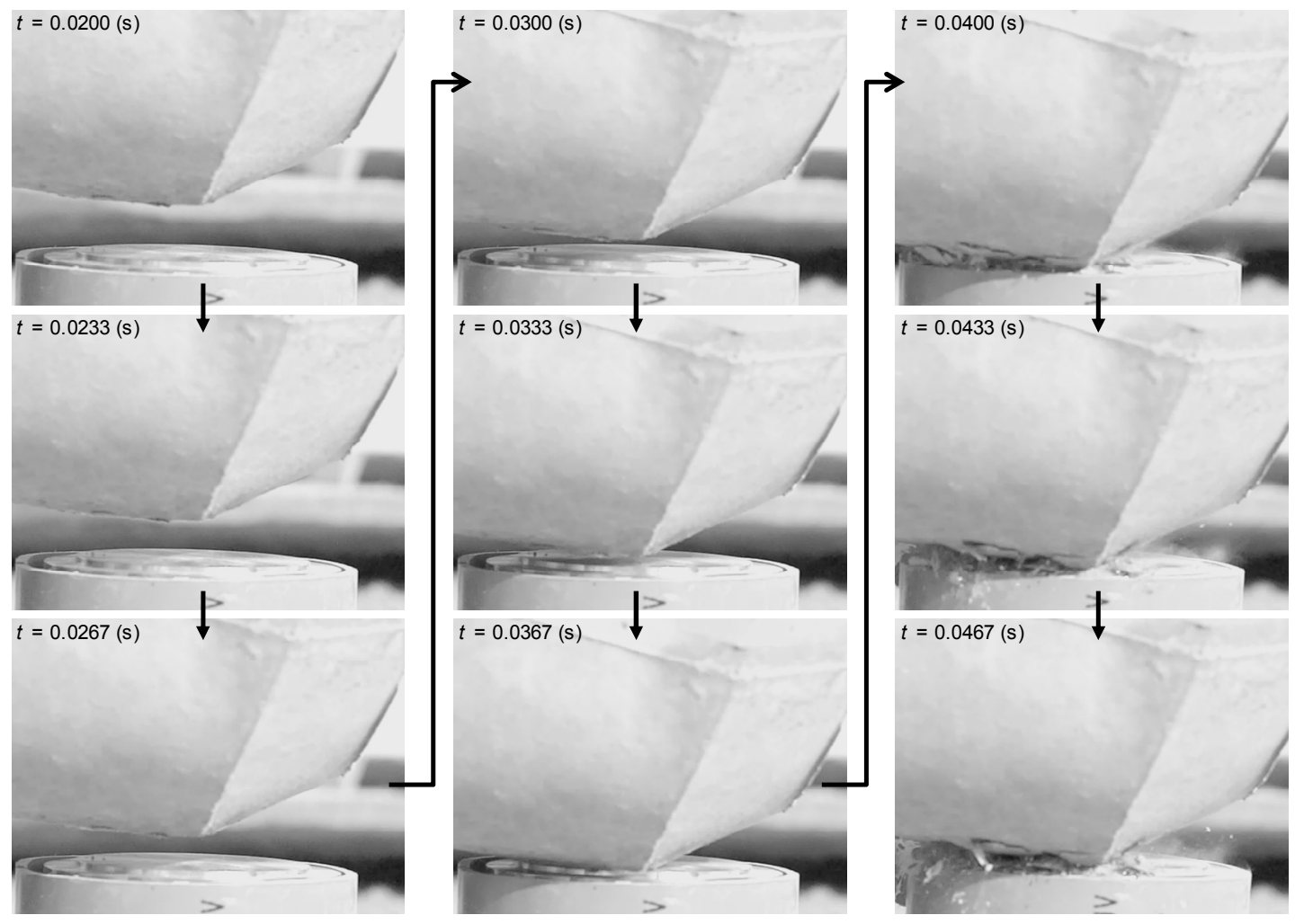

Figure 6. Moment of impact taken by high-speed camera (1840kg block, $\Delta h=25 \mathrm{~cm}, 1 \mathrm{st})$. 


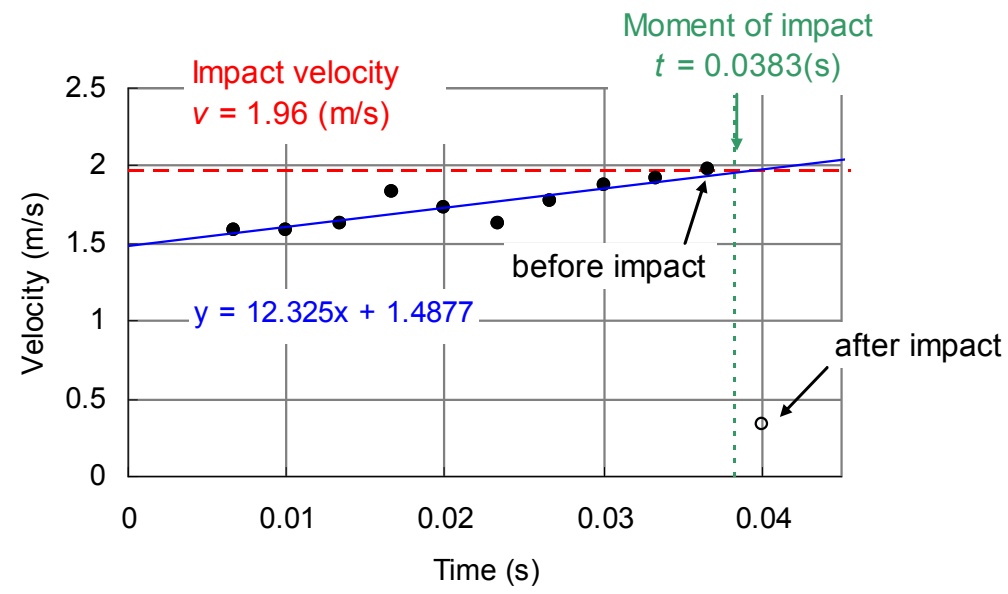

Figure 7. Example of calculation of impact velocity $(1840 \mathrm{~kg}$ block, $\Delta h=25 \mathrm{~cm}, 1 \mathrm{st})$.
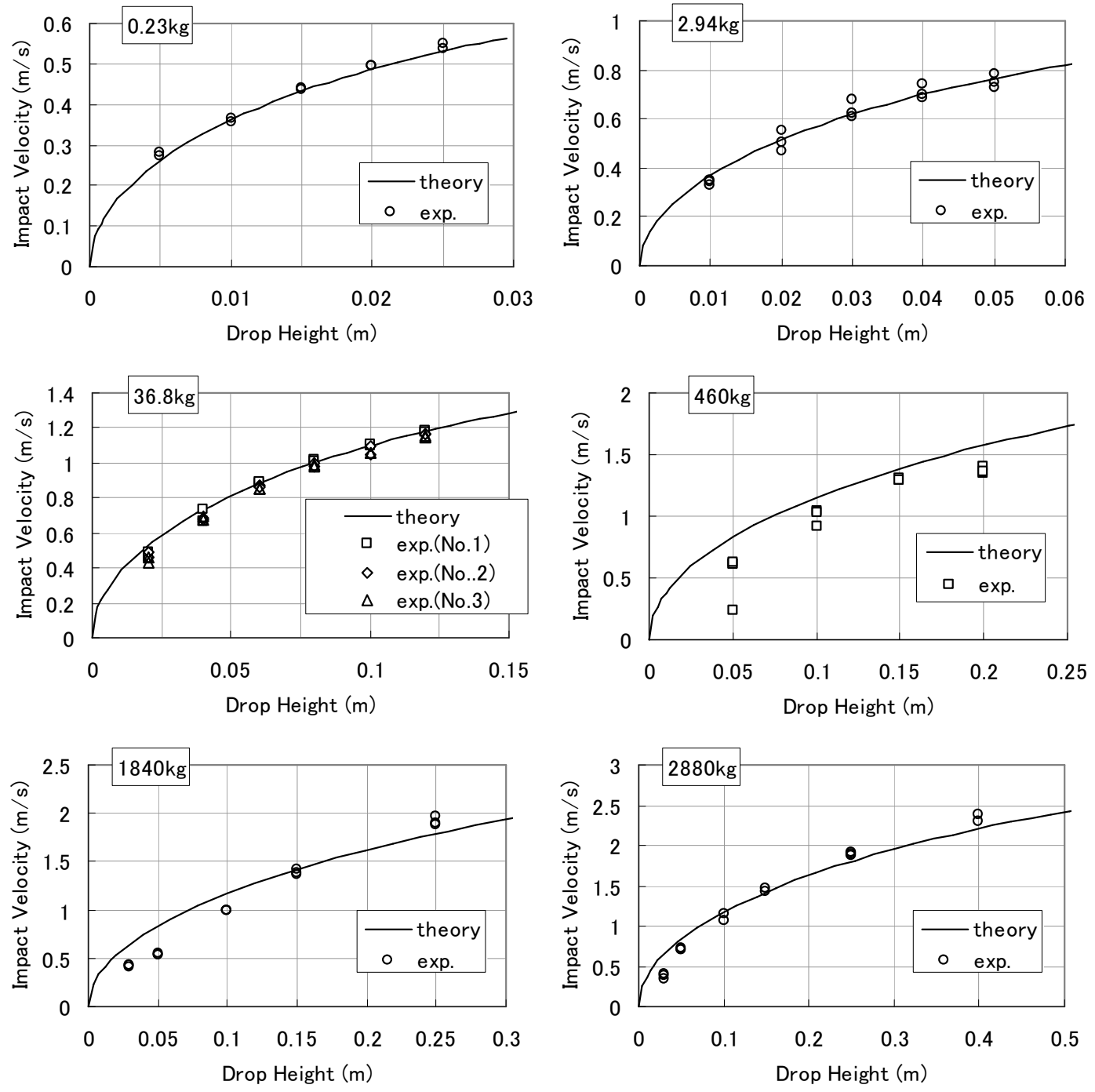

Figure 8. Impact velocities. 

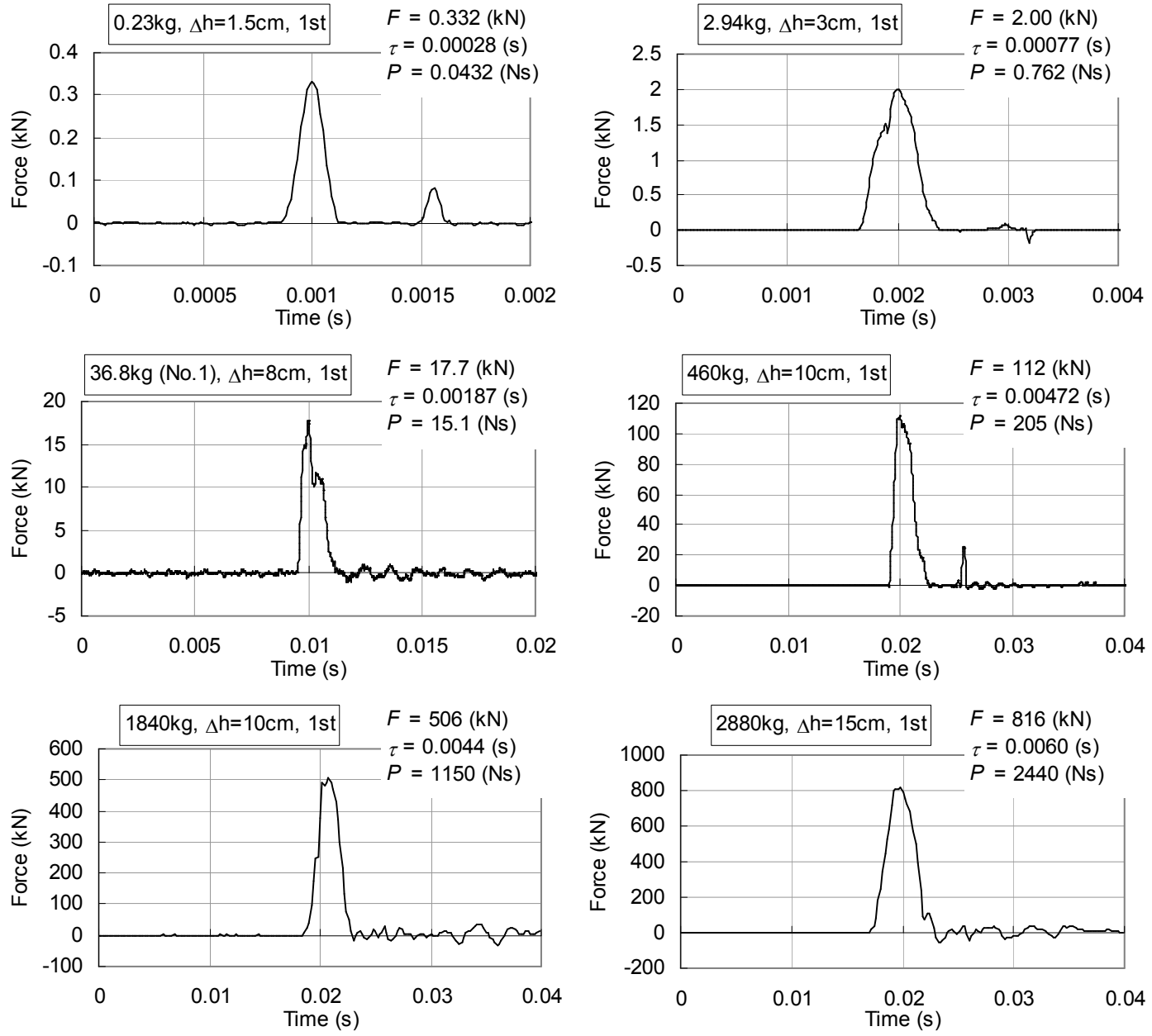

Figure 9. Examples of impact force signals.

Fig. 9 shows examples of the measured impact forces. It can be seen that there is no significant difference in the shape of the impact force signals among each size of block. In order to confirm the validity of Eq. 6, the relation between $\rho D_{\mathrm{n}}{ }^{3} v$ and $P$ is plotted in Fig. 10. Because all the data are plotted on one line of gradient $1: 1$ in the logarithmic graph, it is clear that impulse $P$ is proportional to $\rho D_{\mathrm{n}}{ }^{3} v$, and that Eq. 6 is appropriate. Fig. 11 shows the relation between $D_{\mathrm{n}}$ and $\alpha_{1}$. It is found that $\alpha_{1}$ is independent of the size of the block and is almost constant. This fact indicates that no scale effects exist in this relation. An average value of $\alpha_{1}$ is also shown with a thick broken line in the figure. The average value was obtained by averaging the mean value of $\alpha_{1}$ of each block size. The average value of $\alpha_{1}$ was calculated to 0.453 . 


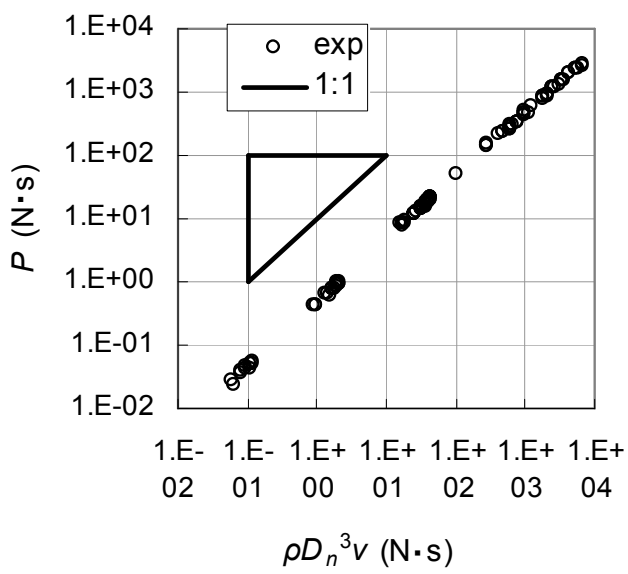

Figure 10. Relation between $\rho D_{n}^{3} v$ and impulse $P$.

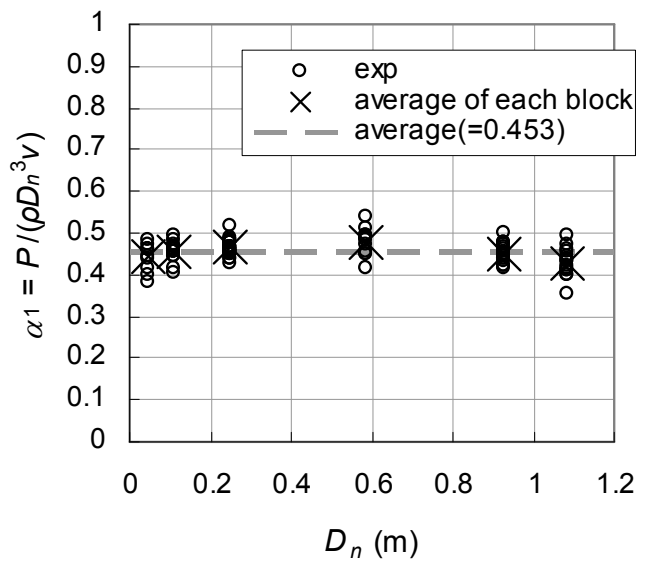

Figure 11. Dimensionless parameter $\alpha_{1}$.

Fig. 12 shows the relation between $D_{n} / \sqrt{E / \rho}$ and the duration of impact $\tau$ to confirm the validity of Eq. 8. The duration of impact $\tau$ is almost proportional to $D_{n} / \sqrt{E / \rho}$. The relation between $D_{\mathrm{n}}$ and the proportionality constant $\alpha_{2}$ in Eq. 8 is shown in Fig. 13. Although the data is scattered slightly, significant scale effects do not exist. The average value of $\alpha_{2}$ obtained in the same way was 21.9. The proportionality constant $\alpha_{3}$ in Eq. 9 was also obtained as shown in Fig. 14. The average value of $\alpha_{3}$ was 0.472 .

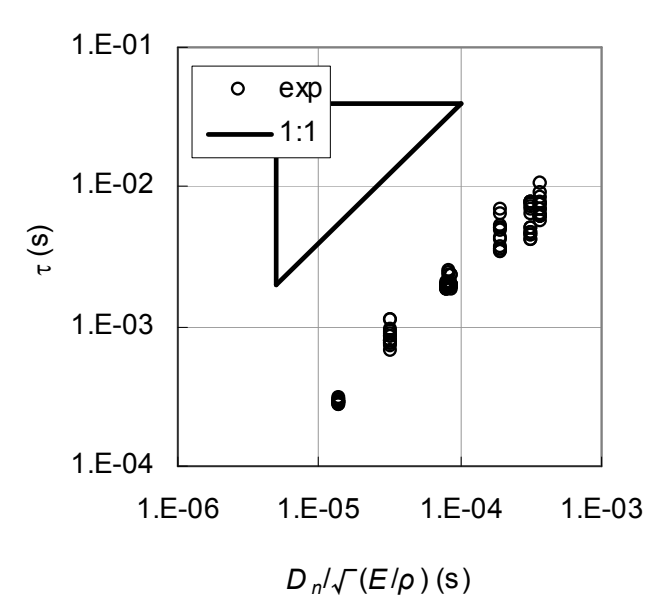

Figure 12. Relation between $D_{\mathrm{n}} / \sqrt{E / \rho}$ and duration $\tau$.

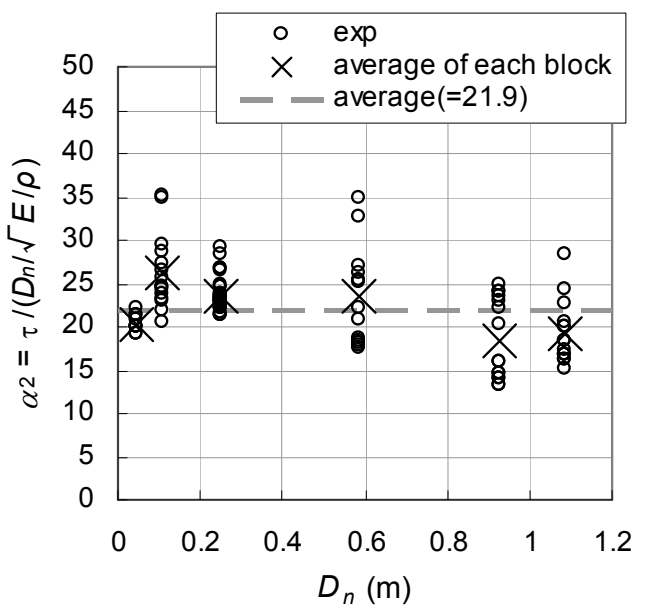

Figure 13. Dimensionless parameter $\alpha_{2}$. 


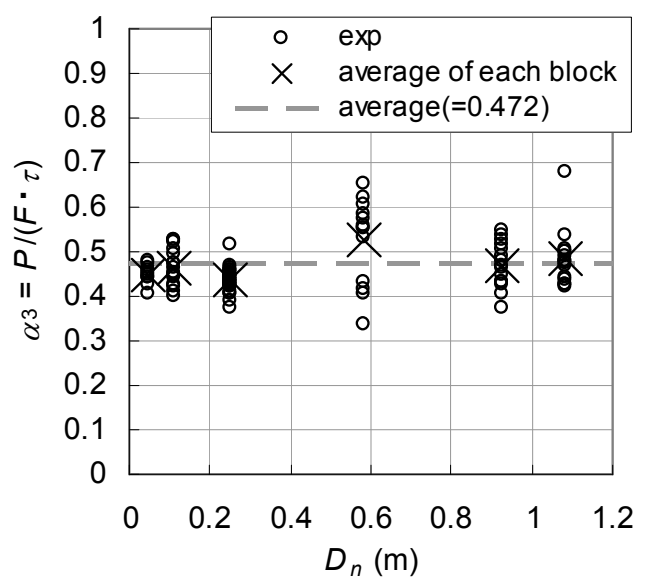

Figure 14. Dimensionless parameter $\alpha_{3}$.

The dimensionless parameters $\alpha_{1}, \alpha_{2}$, and $\alpha_{3}$ for tetrapods were obtained as mentioned above. Substituting these values into Eq. 10, the prediction formula for impact force is obtained as follows:

$$
F=0.0438 \sqrt{\rho E} D_{n}^{2} v
$$

The relation between calculated values from Eq. 11 and measured ones is shown in Fig. 15. The ratio of the measured forces to the calculated ones is shown in Fig. 16. Although they are scattered a little, the predicted values of impact force almost agree with the measured ones and scale effects are not evident. Fig. 17 shows the relative frequency distribution of this ratio. The number of experimental data within $\pm 20 \%$ of the calculated value was $78 \%$ of the total number of data, the number of data within $\pm 30 \%$ was $86 \%$ of the total number of data.

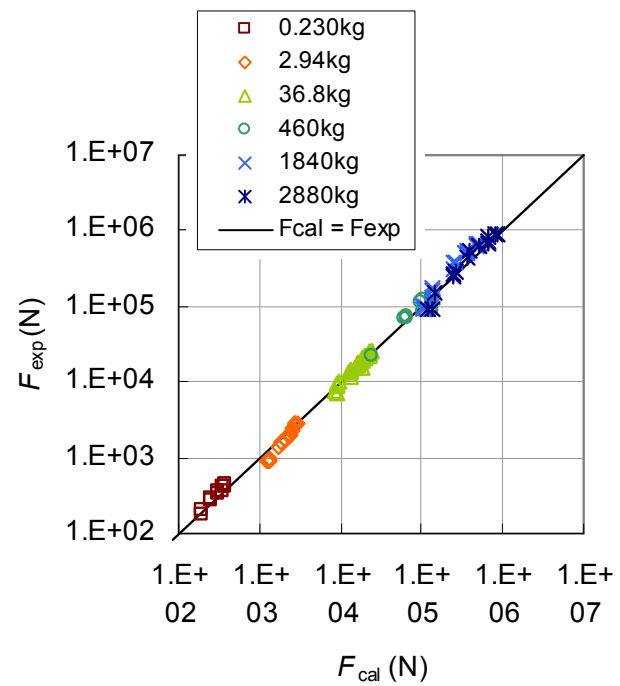

Figure 15. Comparison of the calculated and measured impact forces.

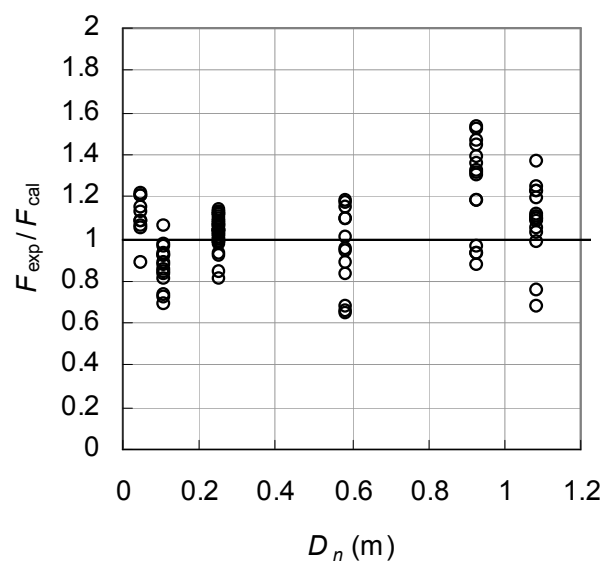

Figure 16. Ratio of the measured impact forces to the calculated ones. 


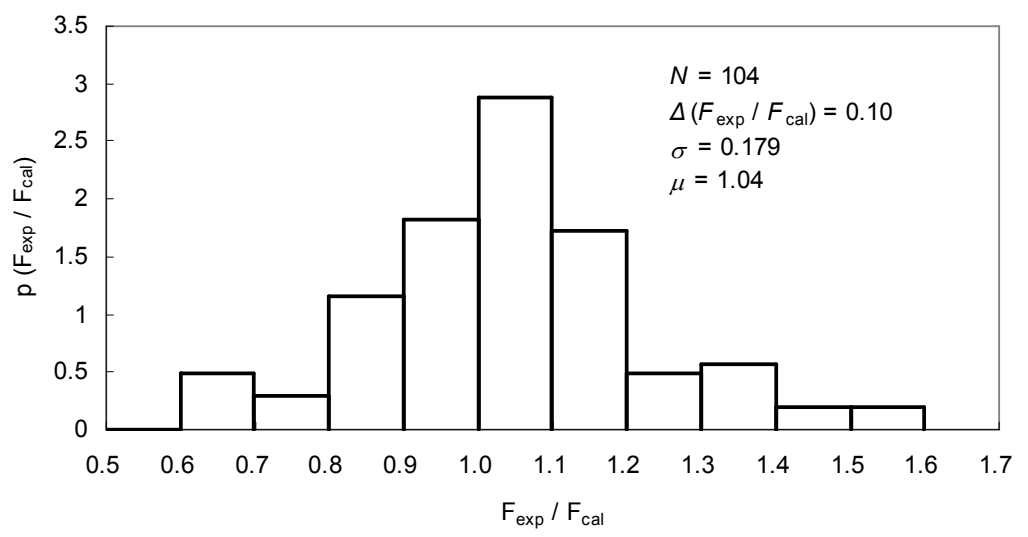

Figure 17. Relative frequency distribution of the $F_{\text {exp }} / F_{\text {cal }}$.

The calculated values mentioned above were obtained using dimensionless parameters $\alpha_{1}, \alpha_{2}$, and $\alpha_{3}$ which were determined by all of the experimental data. It was confirmed whether the same results can be obtained using the easily obtainable small scale drop test data. The parameters $\alpha_{1}, \alpha_{2}$, and $\alpha_{3}$ were calculated again from only the result of small model tests $(0.23 \mathrm{~kg}$ and $2.94 \mathrm{~kg}$ blocks $)$. They became $0.448,23.3,0.457$ respectively. The prediction formula for impact force became as follows:

$$
F=0.0420 \sqrt{\rho E} D_{n}^{2} v
$$

The difference in impact forces obtained from Eq. 11 and Eq. 12 is approximately 4\%. There is no significant difference in estimation compared with the case using all data. Therefore, impact forces on other blocks can be estimated by doing drop tests with small model blocks and determining these parameters.

\section{CONCLUSIONS}

In this study, analysis and measurement of impact forces on wave dissipating concrete blocks due to collisions during rocking motion were conducted. The primal conclusions are as follows:

1. A prediction formula for impact force on concrete blocks due to collision during rocking motion was proposed and its validity was confirmed by drop tests.

2. No scale effects concerning impact force were found to exist in the range of this study.

3. Impact forces can be estimated by using drop tests with small model blocks instead of full-scale drop tests.

\section{REFERENCES}

Burcharth, H.F. 1981. Full-scale dynamic testing of dolosse to destruction, Coastal Engineering, 4, 229-251.

d'Angremond, K., J.W. van der Meer, and C.P. van Nes. 1994. Stresses in tetrapod armour units induced by wave action, Proceedings of $24^{\text {th }}$ International Conference on Coastal Engineering, ASCE, 1713-1726.

Nishigori, W., T. Endo, and A. Shimada. 1986. On stress in Tetrapods under wave action, Proceedings of $20^{\text {th }}$ International Conference on Coastal Engineering, ASCE, 2119-2132.

Terao, T., K. Terauchi, S. Uchida, N. Shiraishi, K. Kobayashi, and H. Gahara. 1982. Prototype testing of Dolosse to destruction, Proceedings of $18^{\text {th }}$ International Conference on Coastal Engineering, ASCE, 2062-2078.

van der Meer, J.W., and G. Heydra. 1991. Rocking armour units: Number, location and impact velocity, Coastal Engineering, 15, 21-39. 